\title{
Qualidade pós-colheita dos frutos do Umbuzeiro (Spondias tuberosa) submetidos ao recobrimento com Fécula de Mandioca e PVC
}

Postharvest quality of Umbuzeiro fruits (Spondias tuberosa) submitted to coating with Cassava Starch and PVC

Calidad postcosecha de las frutas de Umbuzeiro (Spondias tuberosa) sometido a recubrimiento con Almidón de Yuca y PVC

Recebido: 06/01/2021 | Revisado: 07/01/2021 | Aceito: 10/01/2021 | Publicado: 12/01/2021

Beatriz Lopes da Costa

ORCID: https://orcid.org/0000-0002-0482-2832 Instituto Federal de Educação, Ciência e Tecnologia do Rio Grande no Norte, Brasil E-mail: costabialopes1705@gmail.com

Pahlevi Augusto de Souza

ORCID: https://orcid.org/0000-0002-7964-3193 Instituto Federal de Educação, Ciência e Tecnologia do Rio Grande no Norte, Brasil

E-mail: pahlevi10@hotmail.com

Ênio Rafael de Medeiros Santos

ORCID: https://orcid.org/0000-0001-6653-6551 Instituto Federal de Educação, Ciência e Tecnologia do Rio Grande no Norte, Brasil

Email: enio.medeiros@ifrn.edu.br

Bernardino Galdino de Sena Neto

ORCID: https://orcid.org/0000-0001-5922-5093

Instituto Federal de Educação, Ciência e Tecnologia do Rio Grande no Norte, Brasil

E-mail: galdino.sena@gmail.com

Saint Clair Lira Santos

ORCID: https://orcid.org/0000-0002-2738-2972

Instituto Federal de Educação, Ciência e Tecnologia do Rio Grande no Norte, Brasil E-mail: saint.lira@ifrn.edu.br

Greyce Kelly da Silva Lucas

ORCID: https://orcid.org/0000-0001-8745-6729

Instituto Federal de Educação, Ciência e Tecnologia do Rio Grande no Norte, Brasil E-mail: greyce23lully@gmail.com

Raquel Januário da Silva

ORCID: https://orcid.org/0000-0002-2370-8322 Instituto Federal de Educação, Ciência e Tecnologia do Rio Grande no Norte, Brasil E-mail: raqueljanuario97@gmail.com

João Paulo Moraes da Rocha

ORCID: https://orcid.org/0000-0002-2344-6211 Instituto Federal de Educação, Ciência e Tecnologia do Rio Grande no Norte, Brasil E-mail: paulinhot34@gmail.com

Lúcia Cesar Carneiro

ORCID: https://orcid.org/0000-0002-8336-4496 Instituto Federal de Educação, Ciência e Tecnologia do Rio Grande no Norte, Brasil E-mail: lucia.cesar@ifrn.edu.br

\begin{abstract}
Resumo
Estudos recentes têm avaliado o efeito do uso de biofilmes como recobrimento em frutas e hortaliças, pretendendo reduzir o metabolismo respiratório e a transpiração dos mesmos. Logo, objetivou- se avaliar a qualidade pós-colheita de frutos do umbuzeiro submetidos ao recobrimento com fécula de mandioca e PVC. Os frutos foram colhidos na cidade de Campo Redondo-RN e transportados ao IFRN, campus Currais Novos. Os frutos foram sanitizados e submetidos após a secagem aos recobrimentos com fécula de mandioca a 3\% e filme PVC. Em seguida os frutos foram armazenados a temperatura de $24^{\circ} \mathrm{C}$ e umidade relativa de $44 \%$. Analisou-se perda de massa, aparência externa, coloração da casca, diâmetro longitudinal e transversal, pH, acidez titulável, sólidos solúveis e ratio. Verificou-se que a aplicação do recobrimento com PVC nos frutos apresentou efetividade maior em comparação ao revestimento com fécula proporcionando melhor aparência dos frutos, menor perda de água e menor teor de sólidos solúveis ao final do armazenamento. $\mathrm{O}$ uso do revestimento com fécula de mandioca a 3\% não se mostrou eficiente em reduzir a perda de massa, causou maior redução no diâmetro e atrasou o amarelecimento dos frutos. A vida útil dos frutos recobertos com fécula de mandioca a $3 \%$ foi de 3 dias, enquanto os frutos recobertos com PVC e os frutos controle foi de 4 dias.
\end{abstract}


Palavras-chave: Frutos nativos; Revestimento; Vida útil.

\begin{abstract}
Recent studies have evaluated the effect of the use of biofilms as coating on fruits and vegetables, intending to reduce respiratory metabolism and sweating. Therefore, the objective was to evaluate the postharvest quality of umbu tree fruits submitted to cassava starch and PVC coating. The fruits were harvested in the city of Campo Redondo-RN and transported to IFRN, Currais Novos campus. The fruits were sanitized and submitted after drying coatings with $3 \%$ cassava starch and PVC film. Then the fruits were stored at $24^{\circ} \mathrm{C}$ and relative humidity of $44 \%$. Mass loss, external appearance, peel color, longitudinal and transverse diameter, $\mathrm{pH}$, titratable acidity, soluble solids and ratio were analyzed. It was verified that the application of PVC coating on fruits showed higher effectiveness compared to starch coating providing better fruit appearance, lower water loss and lower soluble solids content at the end of storage. The use of the coating with cassava starch at 3\% was not efficient in reducing the loss of mass, caused a greater reduction in diameter and delayed the yellowing of the fruits. The shelf life of fruits covered with cassava starch at $3 \%$ was 3 days, while the fruits covered with PVC and the control fruits were 4 days.
\end{abstract}

Keywords: Native fruits; Coating; Shelf life.

\title{
Resumen
}

Estudios recientes han evaluado el efecto del uso de biopelículas como recubrimiento en frutas y verduras, con la intención de reducir el metabolismo respiratorio y la sudoración. Por lo tanto, el objetivo era evaluar la calidad postcosecho de los frutos de umbu sometidos a almidón de yuca y recubrimiento de PVC. Los frutos fueron cosechados en la ciudad de Campo Redondo-RN y transportados al IFRN, campus de Currais Novos. Los frutos fueron desinfectados y sometidos después de secar los recubrimientos con 3\% de almidón de yuca y película de PVC. A continuación, los frutos se almacenaron a $24^{\circ} \mathrm{C}$ y una humedad relativa del $44 \%$. Se analizaron la pérdida de masa, la apariencia externa, el color de la piel, el diámetro longitudinal y transversal, el pH, la acidez valorable, los sólidos solubles y la relación. Se verificó que la aplicación de recubrimiento de PVC en frutas mostró una mayor eficacia en comparación con el recubrimiento de almidón, proporcionando una mejor apariencia de la fruta, menor pérdida de agua y menor contenido de sólidos solubles al final del almacenamiento. El uso del recubrimiento con almidón de yuca al 3\% no fue eficiente en la reducción de la pérdida de masa, causó una mayor reducción de diámetro y retrasó el amarilleo de los frutos. La vida útil de las frutas cubiertas con almidón de yuca al 3\% fue de 3 días, mientras que las frutas cubiertas con PVC y las frutas de control fueron de 4 días.

Palabras clave: Frutas nativas; Revestimento; Cida útil.

\section{Introdução}

É notório que o Brasil domina uma das maiores variedades de espécies frutíferas em todo o mundo. Existem grupos que ainda são desconhecidas, outras não muito exploradas.

Sendo assim, o fruto de umbu (Spondias tuberosa) vem alcançando espaço, uma vez que, além de ter sabor e aroma característicos, é uma matriz nutritiva e o seu consumo contribui a alimentação. No entanto, por sua alta condição de perecibilidade, o mesmo acaba por ser consumido na região de origem (Barroso, 2017; Souza, 2016).

Normalmente, as perdas pós colheita de frutos e hortaliças ocorrem por manipulação inadequada dos produtos, alteração por pragas e doenças, condições ruins de infraestrutura de armazenamento, ausência de cadeia de frio, promovendo a falta de capacidade de atender as necessidades do setor agrícola (Chitarra \& Chitarra, 2005).

Desse modo, a vida útil pós colheita dos frutos de umbuzeiro é limitada, durando apenas cerca de 2 a 3 dias em condições ambientes, o comportamento e a complexidade do amadurecimento são característicos mudanças bioquímicas e fisiológicas do umbu por indução da taxa de respiração desse fruto comumente climatérico (Teodosio, 2019).

Estudos recentes voltados a descobrir o efeito do revestimento de produtos vegetais por aplicação de biofilmes, pretendendo atrasar o metabolismo respiratório e a transpiração dos mesmos. Para este propósito, são efetuados testes a base de proteínas, amido e outros (Souza et al., 2009).

O método de preservação de frutas e hortaliças conhecido por atmosfera modificada, em que, se utiliza filmes plásticos, as quais as trocas gasosas e a perda de água são limitadas para o ambiente, aumenta o tempo de vida pós-colheita. Porém, o uso desses filmes plásticos causa um nítido impacto ambiental. Dessa forma um dos métodos para recobrimento 
aplicados em frutas e nas hortaliças, objetivando garantir aparência brilhosa e atraente, reduzir a perda de umidade e abaixamento do índice de respiração, consiste no emprego das películas que podem ser ingeridas. Então, a fécula obtida da mandioca é considerada a matéria-prima mais apropriada na formação de biofilmes comestíveis (Silva, Rocha, Pimentel \& Klososki, 2016).

O trabalho objetivou avaliar a qualidade pós-colheita dos frutos do umbuzeiro (Spondias tuberosa) submetidos ao recobrimento com fécula de mandioca e PVC.

\section{Metodologia}

O estudo consiste em uma pesquisa laboratorial de tipo exploratório e descritiva com delineamento experimental e natureza quantitativa. Os frutos de umbu foram colhidos com coloração branco esverdeado, firmes com aspecto liso e brilhante em maio de 2019, no município de Campo Redondo, situado no Rio Grande do Norte, localizado na cidade de Currais NovosRN. Em seguida, foram selecionados quanto à coloração, uniformidade quanto ao tamanho, sem defeitos aparentes como doenças e danos. Todos os frutos foram submetidos a sanitização a 200 ppm de cloro ativo por cerca de 15 minutos, após isso a secagem ocorreu a temperatura ambiente.

Os frutos sanitizados e secos naturalmente foram imersos na solução de fécula de mandioca a $3 \%$ por 1 minuto (Figura 1), retirado e postos sobre as bandejas de isopor. Para o recobrimento PVC (cloreto de polivinila), foi utilizado uma camada simples de filme da marca WYDA®, com espessura de $10 \mu$. Os frutos controle foram deixados sem recobrimentos. Posteriormente, os frutos foram acondicionados em bandejas de isopor e mantidos a temperatura média de $24,6 \pm 2{ }^{\circ} \mathrm{C}$ e $44 \pm$ 8\% UR monitoradas com auxílio de um termohigrômetro THERMO HYGRO® 100 therm 500 no Laboratório de Química dos Alimentos do IFRN- Campus Currais Novos.

Figura 1. Elaboração do revestimento a base de fécula de mandioca a 3\% e imersão dos frutos.
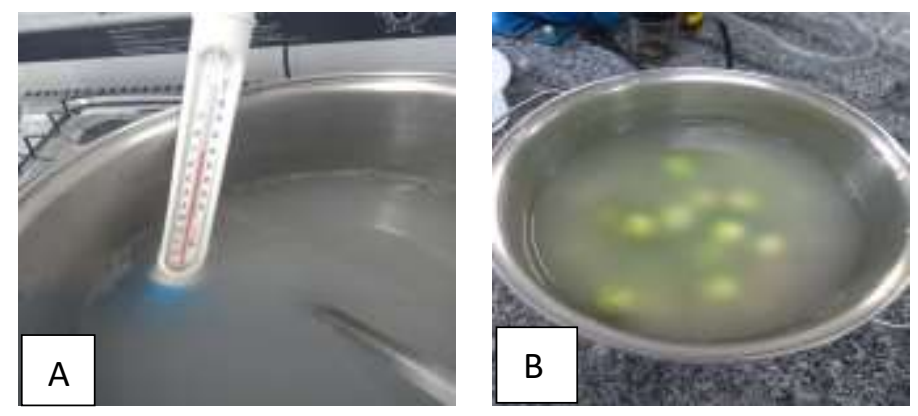

Fonte: Autores (2019).

Utilizou-se como recobrimento a solução de fécula de mandioca a 3\% utilizando-se $30 \mathrm{~g}$ de fécula em $1 \mathrm{~L}$ de água, submetendo ao aquecimento até $70^{\circ} \mathrm{C}$ por cerca de 30 minutos agitando periodicamente (Figura 1). O resfriamento da solução de fécula ocorreu a temperatura ambiente para a imersão dos frutos na solução.

Utilizou-se o delineamento experimental inteiramente casualizado em esquema fatorial $3 \times 5$, sendo o primeiro fator composto pelos recobrimentos (controle, PVC e solução de fécula de mandioca a 3\%) e o segundo dos tempos de análise $(0,2$, 4, 6 e 8 dias), utilizando-se 3 repetições de 15 frutos por parcela para cada recobrimento, totalizando 585 frutos no experimento. 
Para as análises físicas, foi realizado um acompanhamento da perda de massa ao longo do tempo. Utilizou-se a metodologia de Pizato, Vega, Hernández e Borges (2013). As bandejas contendo os umbus foram pesadas em balanças semianalítica da marca EXACTA ${ }^{\circledR}$ a cada 2 dias. Para a obtenção de dados mais precisos, foram sempre pesados os frutos do último tempo de análise. Os resultados obtidos da perda de massa foram expressos em porcentagem pela equação:

$\%$ Perda de massa $=\frac{(p i-p f)}{p i} \times 100$. Considerando: $\mathrm{Pi}=$ Peso Inicial, $\mathrm{Pf}=$ Peso final

A característica aparência externa foi avaliada com auxílio de escala de notas variando de 5 a 1 , sendo o 5 - excelente, 4- boa, 3-regular, 2- ruim (murchamento), 1-inaceitável (muchamento/ ataque fúngico), e a determinação da coloração de 1 ao 5, sendo em 1- verde (V), 2- 75\% verde 25\% amarelado (VA), 3- 50\% amarelo 50\% verde (AV), 4- totalmente amarelo (TA) e 5- maturação avançada (MA) segundo metodologias propostas por Carvalho, Nogueira e Mattietto (2015), Freitas, P. A. de Souza, Coelho, F. X. de. Souza e Beserra (2017).

Os diâmetros longitudinal e transversal foram avaliados com auxílio de um paquímetro digital da marca DIGIMESS ${ }^{\circledR}$.

Para a obtenção do extrato para realização das análises químicas (pH, acidez titulável, sólidos solúveis), foi utilizado um processador para frutas da marca MONDIAL ${ }^{\circledR}$ modelo CF02- 250W, sem adição de água.

A determinação do $\mathrm{pH}$, foi realizada utilizando-se os extratos em potenciômetro de marca ORION STAR ${ }^{\circledR}$ modelo A215, previamente calibrado em pH 4 e 7 (Instituto Adolfo Lutz [IAL], 2008).

A acidez titulável foi determinada utilizando $2 \mathrm{~g}$ do suco pesado em balança semi-analítica, marca KWAGEN ${ }^{\circledR}$, titulando-se com $\mathrm{NaOH}$ a $0,1 \mathrm{~N}$, com a utilização de um pHmetro até a amostra chegar em um pH entre 8,2-8,4, expressa em \% de ácido cítrico (IAL, 2008).

O teor de sólidos solúveis foi determinado utilizando-se o extrato dos frutos em refratômetro de marca DIGIT ${ }^{\circledR}$ modelo 107, com os resultados expressos em ${ }^{\circ}$ Brix (IAL, 2008).

O Ratio foi obtido através da razão entre sólidos solúveis e acidez titulável (IAL, 2008).

Os dados foram apresentados através de média e desvio padrão oriundos de 3 repetições de 15 frutos para cada recobrimento, utilizando-se o software EXCEL.

\section{Resultados e Discussão}

Quanto a perda de massa, observou-se aumento da perda de massa ao longo do armazenamento para todos os tipos de recobrimento (Figura 2), sendo menos intenso para os frutos recobertos com PVC. Ao final do experimento verificou-se médias de perda de massa de 37,1\%, 33,4\% e 17,1\% para o controle, fécula a 3\% e PVC, respectivamente. Segundo Chitarra e Chitarra (2005), para a maioria dos frutos é aceitável uma perda de massa máxima de 10\%. A perda de massa é um evento normal que ocorre durante o armazenamento de frutas e hortaliças, resultado principalmente da perda de água decorrente da transpiração dos frutos. 
Figura 2. Perda de massa dos frutos de umbuzeiro armazenados a $24,6 \pm 2{ }^{\circ} \mathrm{C}$ e UR de $44 \pm 8 \%$ durante 8 dias.

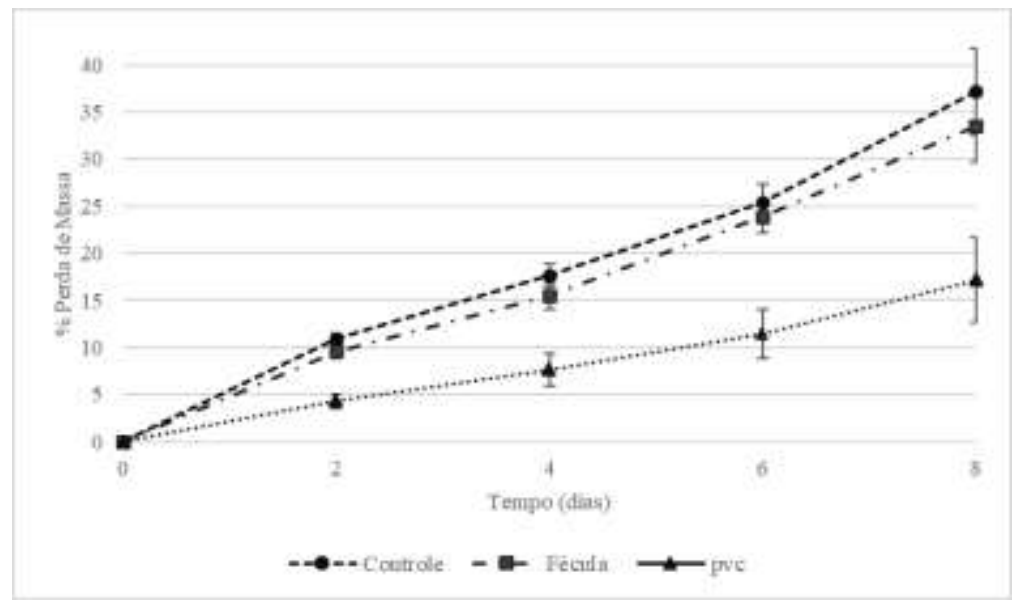

Fonte: Autores (2019).

Segundo Soares (2016), um dos fatores que ocasiona a transpiração é a pressão de vapor da umidade interna do fruto quando se encontra maior que a do ambiente, gerando perda de água.

Alves, Silva, Santos, Silva e Dantas (2020), avaliando o comportamento dos frutos de umbuzeiro submetidos a condições de atmosfera modificada e ambiente natural, observaram maior perda de massa para os frutos controle e resultados menores para os frutos recobertos com PVC. Os mesmos autores concluíram que os frutos apresentam elevada perda de massa em temperatura ambiente em relação a frutos armazenados sob refrigeração.

Pelas características hidrofílicas dos filmes a base de polissacarídeos, esses não formam barreias contra o vapor de água. Os resultados obtidos por Freitas et al. (2017), estão de acordo com os observados na atual pesquisa, pois verificaram que a fécula de mandioca auxilia no controle de gases e diminuição do metabolismo, porém não apresenta eficiência para controlar perda de água.

Em relação ao uso do filme plástico, Alves et al. (2020) citam que essa camada constitui em uma barreira física eficiente quando se trata de transpiração, além de reduzir a respiração (acúmulo de $\mathrm{CO}_{2}$ e redução de $\mathrm{O}_{2}$ ) dentro da embalagem.

Observou-se perda da aparência externa ao longo do período de armazenamento para todos os recobrimentos estudados (Figura 3). No quarto dia de armazenamento apenas o tratamento controle e PVC apresentavam-se com qualidade comercial (notas $\geq 3,0$ ).

Posteriormente, todos os recobrimentos apresentaram-se sem condições de comercialização. A perda de qualidade externa foi causada por murchamento dos frutos, aparecimento de manchas escuras e fungos. 
Figura 3. Aparência Externa dos frutos de umbu durante oito dias de armazenamento a $24,6 \pm 2{ }^{\circ} \mathrm{C}$ a $44 \pm 8 \%$ UR sob atmosfera ambiente (AA).

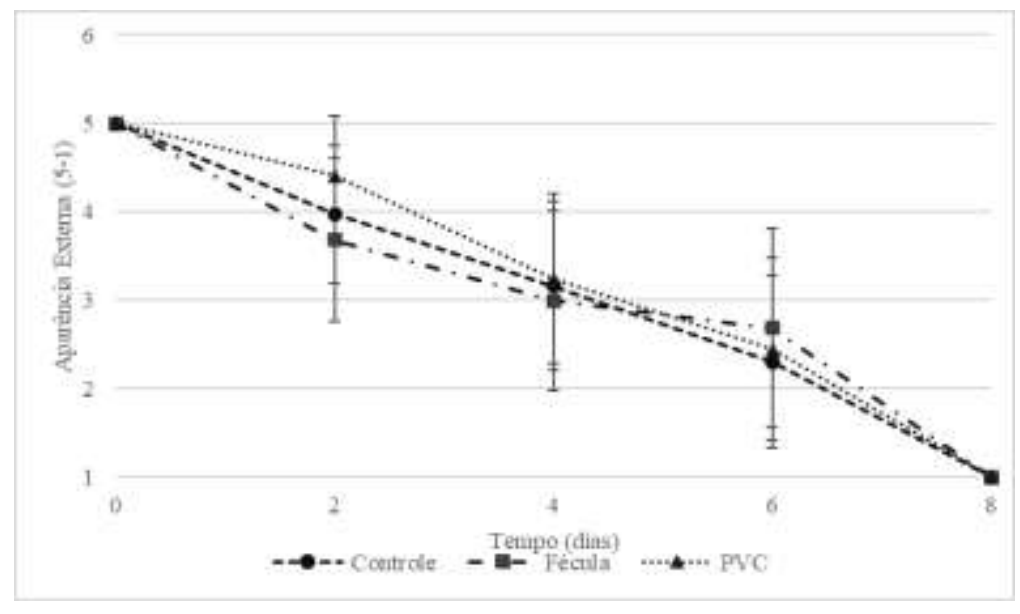

Fonte: Autores (2019).

Freitas et al. (2017), avaliando o revestimento de cajás com fécula de mandioca e filme PVC em condições ambientes durante oito dias, verificaram que ao final do trabalho o aspecto externo permaneceu com boa aparência no tratamento de filme PVC e valores menores com a fécula, ainda assim, este último apresentou melhor aparência dos frutos em relação ao controle. França et al. (2018), estudando o revestimento com amido em manga Tommy Atkins sob refrigeração durante 25 dias, observaram que a aparência permaneceu boa durante um tempo significativo. No presente estudo o revestimento com fécula apresentou vida útil de apenas 3 dias, resultado esse provavelmente causado pela ineficiência do amido em ser uma barreira de retenção de perda de água e pelo comportamento hidrofílico do recobrimento.

Quanto a coloração dos frutos, observou-se alteração para todos os tratamentos, passando de verde claro à amarelo Figura 4, 5, 6, 7 e 8. Observou-se também atraso na mudança de cor para os frutos recobertos com fécula, sendo bastante visível ao quarto dia de armazenamento (Figura 6 B). A mudança de cor é importante para os consumidores, pois passa uma informação que o fruto está maduro.

Figura 4. Frutos do umbuzeiro dos tratamentos controle (A), fécula a 3\% (B) e PVC (C) no tempo 0.
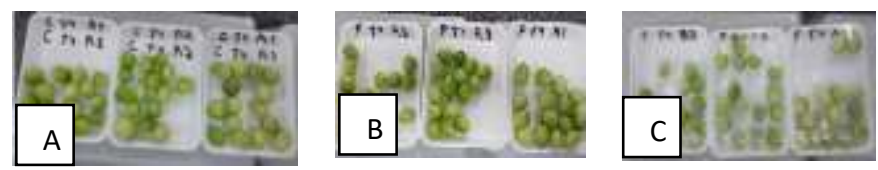

Fonte: Autores (2019).

Figura 5. Frutos do umbuzeiro dos tratamentos controle (A), fécula a 3\% (B) e PVC (C) no segundo dia de armazenamento.
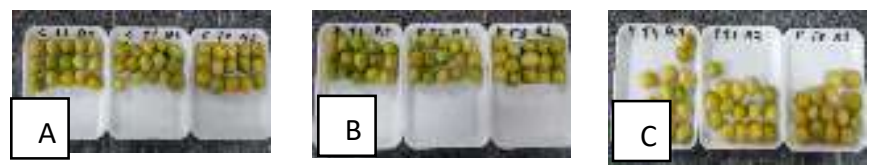

Fonte: Autores (2019). 
Figura 6. Frutos do umbuzeiro dos tratamentos controle (A), fécula a 3\% (B) e PVC (C) no quarto dia de armazenamento.
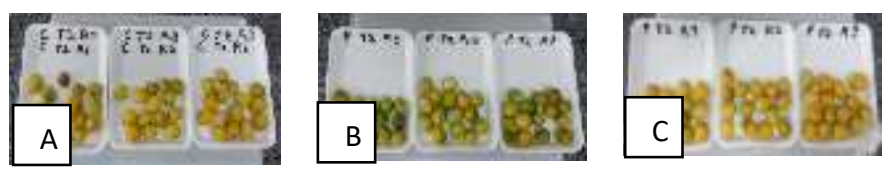

Fonte: Autores (2019).

Figura 7. Frutos do umbuzeiro dos tratamentos controle (A), fécula a 3\% (B) e PVC (C) no sexto dia de armazenamento.
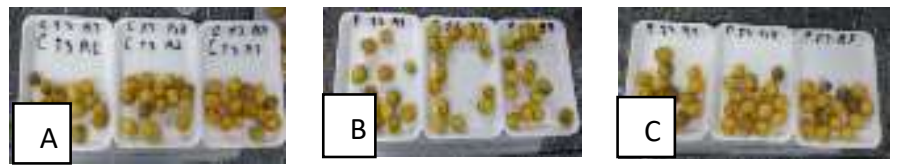

Fonte: Autores (2019).

Figura 8. Frutos do umbuzeiro dos tratamentos controle (A), fécula a 3\% (B) e PVC (C) no oitavo dia de armazenamento.
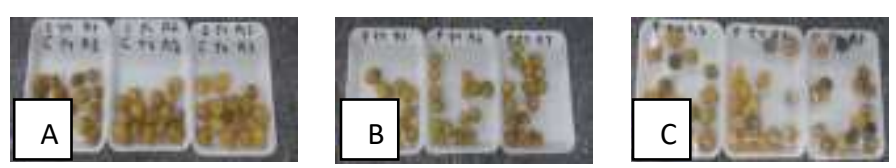

Fonte: Autores (2019).

Freitas et al. (2017), avaliando o recobrimento de cajás com fécula de mandioca e filme plástico PVC, citam que a perda da cor verde é proveniente da degradação da clorofila que ocorre por fatores como síntese da clorofilase, atuação de ácidos, oxidação e alteração do pH. A aplicação da película de mandioca dificulta ação do oxigênio e eleva a concentração do $\mathrm{CO}_{2}$, levando a persistência do pigmento verde, assim corroborando com o observado no trabalho em questão da permanência da cor verde no revestimento fécula. Esse tipo de filme não apresenta de permeabilidade para $\mathrm{O}_{2}$ e $\mathrm{CO}_{2}$ embora apresente para água. Pereira, Souza, Ferreira, Valle e Silva (2019), estudando o uso de biofilmes comestíveis na pós-colheita do cajá, observaram que o uso da fécula atrasou a mudança para a cor amarelada do fruto. Em relação a presente pesquisa, a tonalidade dos frutos foi percebida do verde para o amarelo, em especial, ao quarto dia (Figura $6 \mathrm{C}$ ).

Observou-se redução nos diâmetros longitudinais e transversais (Figura 9 e 10) em todos os recobrimentos estudados, sendo menos intenso para os frutos recobertos com PVC (Figuras 6 e 7). A redução dos diâmetros está relacionada à perda de água dos frutos. Assim, o recobrimento com PVC atrasa esse evento concordando com os dados obtidos para perda de massa (Figura 2). 
Figura 9. Diâmetro longitudinal dos frutos de umbuzeiro armazenados a $24,6 \pm 2{ }^{\circ} \mathrm{C}$ e UR de $44 \pm 8 \%$ durante 6 dias.

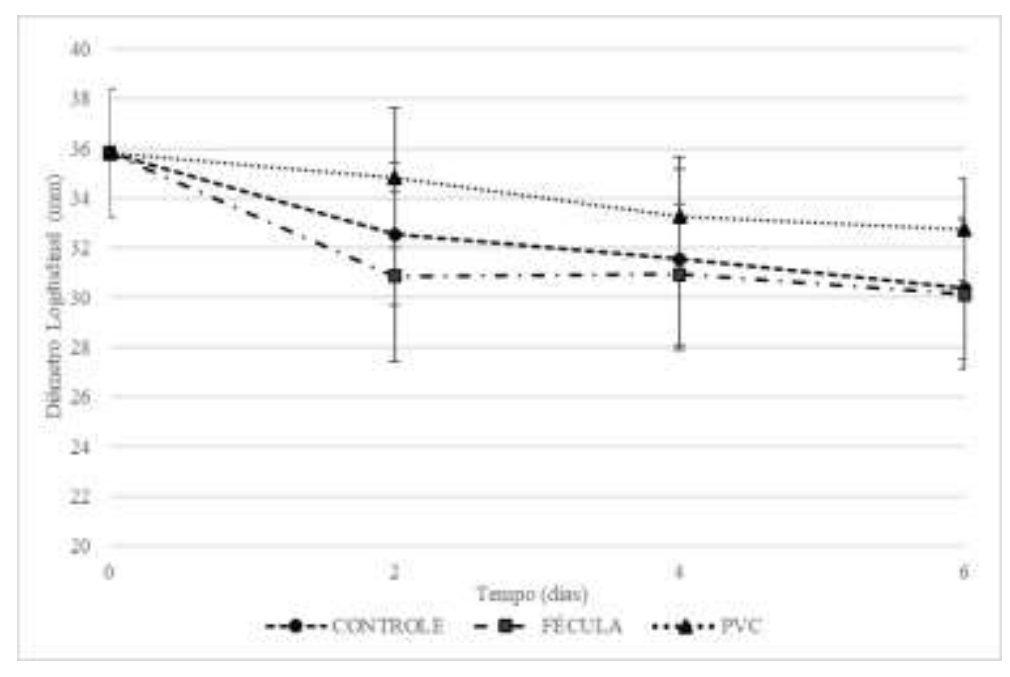

Fonte: Autores (2019).

Figura 10. Diâmetro transversal dos frutos de umbuzeiro armazenados a $24,6 \pm 2{ }^{\circ} \mathrm{C}$ e UR de $44 \pm 8 \%$ durante 6 dias.

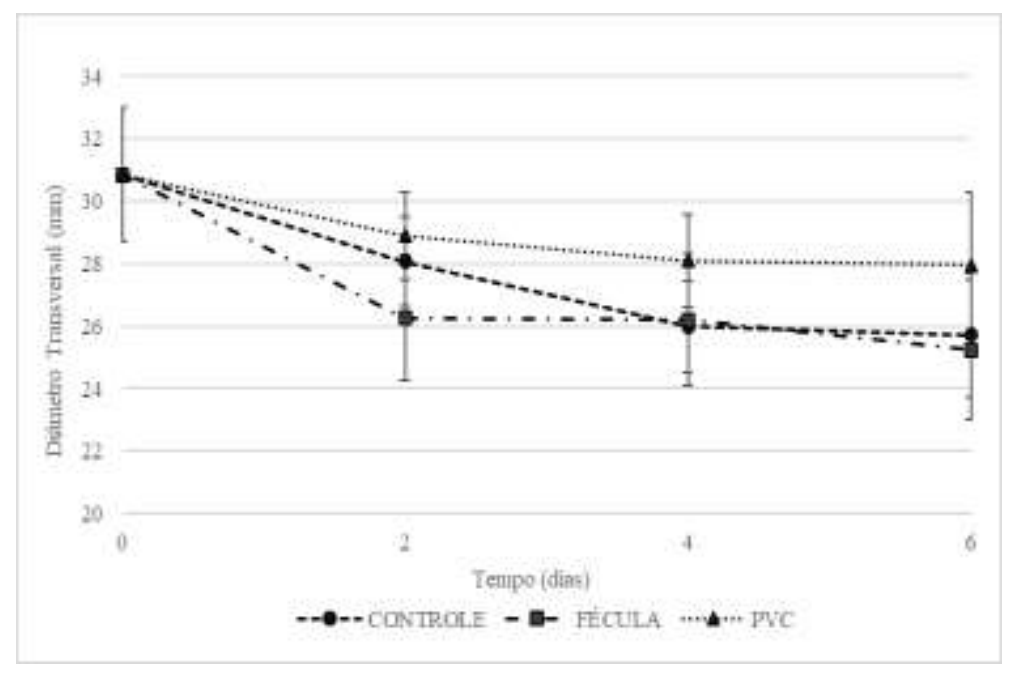

Fonte: Autores (2019).

Silva, Paz, Sousa e Abreu (2019), avaliando o armazenamento de umbus recobertos com filme plástico PVC, verificaram redução nos valores dos diâmetros. Os mesmos autores observaram que o efeito do PVC em retardar essa diminuição está ligado a minimização da transpiração.

Menezes et al. (2017), trabalhando com umbu em três estádios de maturação, perceberam que quando verdes mostravam valores 33,5 mm de DL e 27,79 mm DT, os maduros com 28,90 mm DL e 26,62 mm DT. No presente estudo, os dados resultantes de DL foram 32,7 mm (PVC), 30,3 mm (controle) e 30,1 mm (fécula) ao sexto dia. Para o DT foi 27,9 mm (PVC), 25,7 mm (controle) e 25,2 mm (fécula) no último dia, observando assim que a redução foi maior que o resultado de Menezes et al. (2017) e concordando com a Figura 2 de perda de massa que se mostrou maior.

Verificou-se a oscilação mínima do pH referente aos frutos de umbuzeiro nas amostras ao decorrer do armazenamento (Figura 11). Os valores não diferenciaram significativamente, no último dia os tratamentos fécula e PVC chegaram a 2,1 e 2,3 respectivamente. Alves et al. (2020) estudando o gênero Spondias perceberam valores em uma faixa de 1,88 a 3,05, resultados aproximados foram obtidos com os frutos avaliados no atual estudo. 
Figura 11. $\mathrm{pH}$ dos frutos de umbuzeiro armazenados a $24,6 \pm 2{ }^{\circ} \mathrm{C}$ e UR de $44 \pm 8 \%$ durante 6 dias.

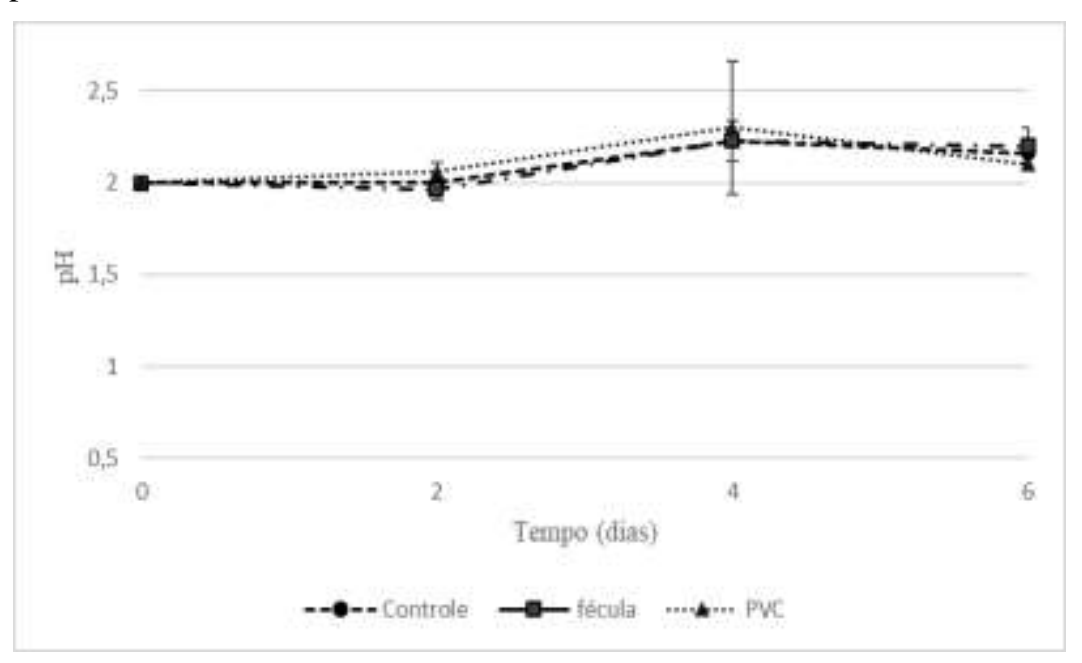

Fonte: Autores (2019).

Teodosio (2019), pesquisando sobre revestimento de umbu com microalga e óleo de romã, percebeu que durante o armazenamento, todos os frutos reduziram os valores de $\mathrm{pH}$ até o terceiro dia $(2,38)$. No quarto e quinto os valores aumentaram, respectivamente de 2,45 para 2,62. O mesmo autor relatou que o umbu geralmente apresenta variação de pH na maturação entre 2,0 a 3,0. O presente estudo apresentou variação das médias em todos os tratamentos, embora os resultados não apresentem mudanças significativas.

Houve oscilação nos teores de acidez titulável durante o armazenamento, não diferindo muito entre os teores iniciais e finais. (Figura 12). Freitas et al. (2017), estudando sobre revestimento para conservação de umbu (Spondias tuberosa), verificaram aumento e posterior redução da acidez titulável ao final do experimento. Os mesmos relataram que o consumo dos ácidos devido ao processo respiratório do fruto leva a diminuição dessa característica.

Figura 12. Acidez titulável dos frutos de umbuzeiro armazenados a $24,6 \pm 2{ }^{\circ} \mathrm{C}$ e UR de $44 \pm 8 \%$ durante 6 dias.

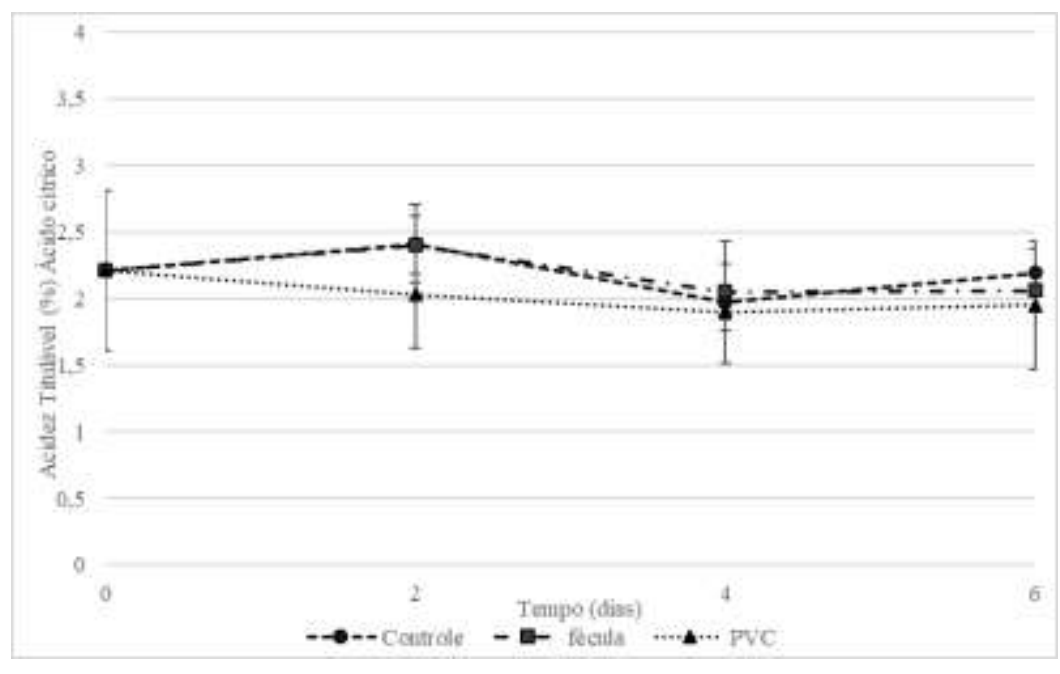

Fonte: Autores (2019).

Souza (2016), pesquisando revestimento de umbu com goma- arábica armazenado em refrigeração, verificou mudanças nos teores de acidez e notou que o recobrimento utilizado quando comparado ao controle foi eficaz para reduzir o amadurecimento por apresentar acidez com valor maior, no entanto o atual estudo mostrou acidez menor, indicando que o revestimento não foi efetivo para atrasar a maturação. 
Para sólidos solúveis (Figura 13), verificou-se aumento dos teores durante o armazenamento. Os teores iniciais de sólidos solúveis foram de $7,23{ }^{\circ}$ Brix e no decorrer de 6 dias aumentaram (com pequenas oscilações), sendo os picos observados no segundo e no sexto dia de armazenamento com o tratamento PVC diferenciando significativamente dos demais, apresentando valor menor de sólidos solúveis de $9,23{ }^{\circ}$ Brix em relação aos demais tratamentos no sexto dia.

Figura 13. Sólidos solúveis dos frutos de umbuzeiro armazenados a $24,6 \pm 2{ }^{\circ} \mathrm{C}$ e UR de $44 \pm 8 \%$ durante 6 dias.

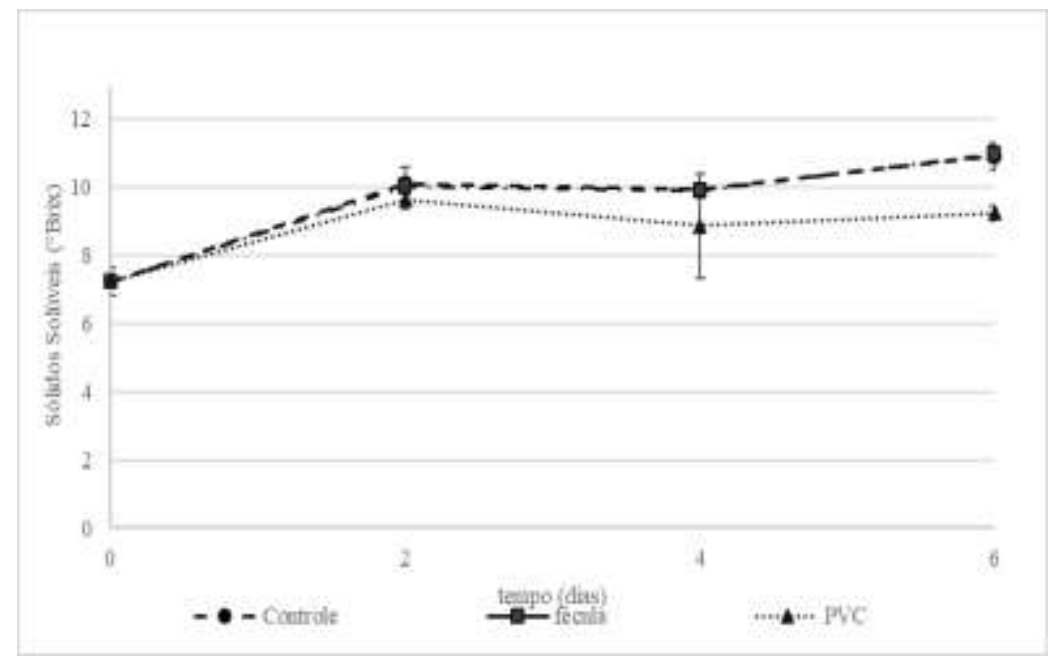

Fonte: Autores (2019).

Nos estádios em transição do tom esverdeado para amarelo (figura 5) foi detectado pico dos valores de sólidos solúveis (SS), quando aos frutos que atingiram a tonalidade amarelada, (figura 6) em especial para o PVC (a fécula com a cor verde predominante) os valores de SS estavam menores e no estado de senescência do fruto (figura 7) ocorreu aumento. N. S. Santos et al. (2020) estudando conservação de S. tuberora por atmosfera modificada sob refrigeração, relacionou baixos teores de sólidos solúveis com o estádio verde e percebeu a ocorrência do aumento de SS com o aparecimento da tonalidade amarela.

V. P. Silva et al. (2019), trabalhando com revestimento de umbu com filme PVC em condições de resfriamento, perceberam que a aplicação dessa película não interferiu nos teores de sólidos solúveis dos frutos. No entanto, detectou decréscimo a partir do terceiro dia $\left(10,89{ }^{\circ}\right.$ Brix). No atual estudo o PVC interferiu, indicando que o tratamento atrasou o amadurecimento do fruto e as oscilações observadas ocorreram no quarto e no sexto dia.

Observou-se aumento da característica ratio (SS/AT) para os tratamentos ao longo do armazenamento (Figura 14). Os frutos recobertos com PVC e os controle apresentaram comportamentos semelhantes com oscilações ao longo do experimento, enquanto os frutos recobertos com fécula apresentarem-se mais estáveis para essa característica. 
Figura 14. Ratio dos frutos de umbuzeiro armazenados a $24,6 \pm 2{ }^{\circ} \mathrm{C}$ e UR de $44 \pm 8 \%$ durante 6 dias.

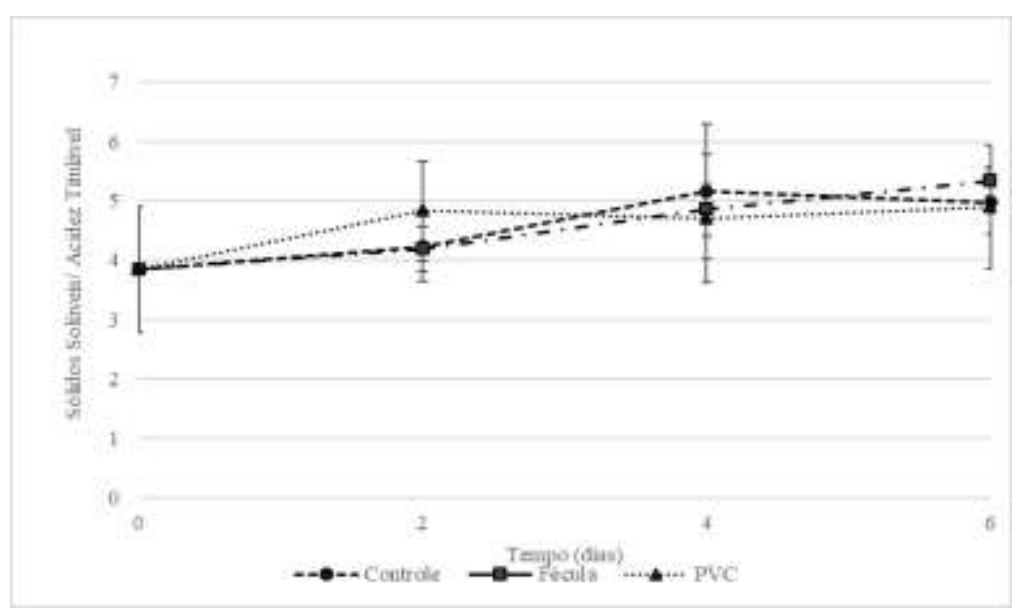

Fonte: Autores (2019).

Pereira et al. (2019). Freitas et al. (2017), pesquisando revestimento comestível e aplicação de filme PVC para conservação de cajá, perceberam aumento dos valores de 5,8 a 7,4 resultados com comportamento semelhante foram encontrados do atual trabalho.

\section{Conclusão}

Verificou-se que a aplicação do recobrimento com PVC nos frutos apresentou efetividade maior em comparação ao revestimento com fécula proporcionando melhor aparência dos frutos, menor perda de água e menor teor de sólidos solúveis ao final do armazenamento.

O uso do revestimento com fécula de mandioca a $3 \%$ não se mostrou eficiente em reduzir a perda de massa, causou maior redução no diâmetro e atrasou o amarelecimento dos frutos.

A vida útil dos frutos recobertos com fécula de mandioca a $3 \%$ foi de 3 dias, enquanto os frutos recobertos com PVC e os frutos controle foi de 4 dias.

Tendo em vista a carência de literatura a respeito dos frutos de umbuzeiro, em especial no estado do Rio Grande do Norte, faz-se necessário a realização de trabalhos utilizando o umbu como objeto de estudo, visto que este tipo de pesquisa será vital para ressaltar o potencial desse fruto. Além disso, torna-se essencial o desenvolvimento de biofilmes a fim encontrar recobrimentos que se adaptem as características do fruto, contribuindo para sua manutenção pós-colheita e que possa ser utilizado para comercialização do fruto.

\section{Referências}

Alves, T. P., Silva, R. A. C., Santos, N. S, Silva, J. C. de. S., \& Dantas, F. A. L. (2020). Qualidade pós-colheita de frutos do umbuzeiro (Spondias tuberosa Arruda) armazenados sob atmosfera modificada. Diversitas Journal. https://periodicos.ifal.edu.br/diversitas_journal/article/view/1193/1030. doi: 10.17648/diversitas-journal-v5i3-1193

Barroso, A. J. R. (2017).Desenvolvimento de Mixes de Mangaba e Umbu Elaborados Com Extrato em Pó de Amendoim Despeliculizado. (Dissertação de mestrado). Universidade Federal de Campina Grande, UFCG, Campina Grande - PB, Brasil. http://dspace.sti.ufcg.edu.br:8080/jspui /bitstream/riufcg/4171/1/ANTONIO\%20JACKSON\%20RIBEIRO\%20BARROSO\%20\%E2\%80\%93\%20DISSERTA\%C3\%87\%C3\%83 O\%20\%28PPGEA\% $29 \% 202017 . p d f$.

Carvalho, A.V., Nogueira, J. G., \& Mattieto, R. de A. (2015) Elaboração e Caracterização de Estruturados de Umbu. Embrapa Amazônia Oriental. https://www.infoteca.cnptia.embrapa.br/infoteca/bitstream/doc/1026494/1/BPD97.pdf

Chitarra, M. I. F., \& Chitarra, A. B. 2005. Pós-colheita de frutos e hortaliças: fisiologia e manuseio. p.785. Lavras: Universidade Federal de Lavras: (2a ed.), 
França, A. F., Santos, I. S., Gomes, J. Jr., \& Costa, J. E. (2018). Revestimentos à base de amido na conservação de mangas Tommy Atkins associados a duas fontes de cálcio e a um agente oxidante em ambiente refrigerado. Revista Principia -Divulgação Científica e Tecnológica do IFPB. https://periodicos.ifpb.edu.br/index.php/principia/article/view/1777. 10.18265/1517-03062015v1n42p102-110

Freitas, R. V. da. S., Souza, P. A., Coelho, E. S., Souza, F. X., \& Beserra, H. N. R. B. (2017). Storage of Mombin Fruits Coated With Cassava Starch and PVC Film. Rev. Caatinga. https://www.scielo.br/scielo.php?script=sci_arttext\&pid=S1983-21252017000100244. https://doi.org/10.1590/1983-21252017v30n127rc

Instituto Adolfo Lutz. (2008). Métodos físico-químicos para análise de alimentos. São Paulo: IAL. http://www.ial.sp.gov.br/resources/editor inplace/ial/2016_3_19/analisedealimentosial_2008.pdf.

Menezes, P. H. S., Souza, A. D., Silva, E. S., Medeiros, R. D., Barborsa, N. C., Soria, D. G. (2017). Influência do estádio de maturação na qualidade físicoquímica de frutos de umbu (Spondias tuberosa). Scientia Agropecuaria. http://www.scielo.org.pe/scielo.php?pid=S207799172017000100007\&script=sci_arttext\&tlng=en. http://dx.doi.org/10.17268/sci.agropecu.2017.01.07

Pereira, L. D., Souza, L. K. F., Ferreira, K. B., Valle, K. D., \& Silva, D. F. P. (2019). Biofilmes Comestíveis na Conservação Pós-Colheita de Cajá. Viçosa, MG, DEA/UFV. Revista Engenharia na Agricultura. https://periodicos.ufv.br/reveng/article/view/883/pdf. 10.13083/reveng.v27i4.883.

Pizato, S., Vega, W. R. C., Hernázdez, C. P., \& Borges, C. D. (2013) Efeito da aplicação de diferentes revestimentos comestíveis na conservação de maçãs 'Royal Gala' minimamente processada. Ciências Agrárias. http://www.uel.br/revistas/uel/index.php/semagrarias/article/download/13144/12030. doi: $10.5433 / 1679-0359.2013 \mathrm{v} 34 \mathrm{n} 1 \mathrm{p} 253$.

Santos, N. S., Silva, J. C. de. S., Araújo, C. de. A., Lima, K. F., \& Silva, F. G. A. da. (2020). Caracterização da conservação refrigerada do umbu (Spondias Tuberosa Arruda Câmara) sob atmosfera modificada. Diversitas Journal. https://periodicos.ifal.edu.br/diversitas_journal/article/view/931/970. doi: 10.17648/diversitas-journal-v5i2-931.

Silva, B. K. O., Rocha, N. D., Pimentel, T. C., \& Klososki, S. J. (2016). Películas de Amido de Mandioca na Conservação Pós-Colheita de Morango, Maracujá e Pimenta Doce. Revista Brasileira de Produtos Agroindustriais. https://www.researchgate.net/publication/3122641 48_Peliculas_de_Amido_de_Mandioca_na_Conservacao_Pos-Colheita_de_Morango_Maracuja_e_Pimenta_Doce. doi: 10.15871/1517-8595/rbpa.v18n3p283291.

Silva, V. P., Paz, M. A., Sousa, K. dos. S. M., \& Abreu, A. K. F. (2019). Qualidade pós-colheita de frutos de umbuzeiro (Spondias tuberosa Arr.) embalados com filme de PVC. Revista Craibeiras de Agroecologia. https://www.seer.ufal.br/index.php/era/article/download/7714/5585.

Soares, R. M. C. (2016). Efeito da Goma Arábica como Revestimento para Prolongamento da Vida Pós-Colheita do Cajá (Spondias mombin L.). (Trabalho de Conclusão de Curso). Universidade Federal da Paraíba- UFPB, João Pessoa, PB, Brasil. https://repositorio.ufpb.br/jspui/bitstream/123456789/1054/1/Soares_Rosalia\%20Efeito\%20da\%20goma\%20arabica.pdf.

Souza, J. C. A. de. Jr. (2016). Avaliação das Características físico-químicas do Umbu (Spondias tuberosa) Com Aplicação de Revestimento Comestível a Base de Goma Arábica. (Trabalho de Conclusão de Curso). Universidade Federal da Paraíba - UFPB, João Pessoa, PB, Brasil https://repositorio.ufpb.br/jspui/bitstream/123456789/1057/1/Souza\%20Junior_Jose\%20Carlos\%20Avaliacao\%20das\%20caracteristicas.pdf

Souza, P. A., Aroucha, E. M. M., Souza, A. E. D., Costa, A. R. F. C., Ferreira, G. S., Bezerra, F. Neto. (2009). Conservação Pós-Colheita de Berinjela com Revestimentos de Fécula de Mandioca ou Filme de PVC. Hortic. Bras. http://www.scielo.br/scielo.php?script=sci_arttext\&pid=S0102-05362009000200020. doi: https://doi.org/10.1590/S0102-05362009000200020

Teodosio, A. E. M. de. (2019) Conservação Pós-Colheita de Umbu Recoberto com Microalga e Óleo da Semente da Romã. Dissertação de Mestrado. Universidade Federal de Campina Grande- UFCG. Pombal, Brasil. http://dspace.sti.ufcg.edu.br:8080/jspui/bitstream/riufcg/3305/1/AL BERT\%20EINSTEIN\%20MATHIAS\%20DE\%20MEDEIROS\%20TEOD\%C3\%93SIO\%20-\%20DISSERTA\%C3\%87\%C3\%83O\%20-

\%20PPGHT\%202019.pdf. 